\title{
Methods of mathematical modeling using polynomials of algebra of sets
}

\author{
Alexandr Kazanskiy ${ }^{1, *}$ and Ivan Kochetkov ${ }^{1}$ \\ ${ }^{1}$ Moscow State University of Civil Engineering, Yaroslavskoye sh. 26, Moscow, 129337, Russia
}

\begin{abstract}
The article deals with the construction of discrete mathematical models for solving applied problems arising from the operation of building structures. Security issues in modern high-rise buildings are extremely serious and relevant, and there is no doubt that interest in them will only increase. The territory of the building is divided into zones for which it is necessary to observe. Zones can overlap and have different priorities. Such situations can be described using formulas algebra of sets. Formulas can be programmed, which makes it possible to work with them using computer models.
\end{abstract}

\section{Introduction}

At present, high-rise construction in our country is gaining wide scope. In this regard, there are also issues of safety of maintenance of such buildings. This is due not only to fire safety, but also to possible criminal and environmental threats. Proceeding from what has been said, in this article we will consider the creation of a discrete model based on methods of set theory to solve the problems of securing high-rise buildings.

The basic concepts of set theory were introduced by Dedekind in 1871 and then by his friend George Cantor. Operations on sets make it possible to form new sets of initial sets. This enables the use of sets for various practical tasks, such as the classification of any objects, analysis of various types of sociological research, analysis of data from which it is necessary to select data characterized by specific properties.

A set may be viewed as collection of objects, the elements or members of the set. We ordinarily use capital letters, A, B, C,..., to denote sets, and lowercase letters a, b, c,..., to denote elements of sets. In any application of the theory of sets, the members of all sets usually belong to some fixed large set called the universal set. A universal set is usually denoted by the symbol U. All sets under consideration at a particular time are subset of a fixed universal set $U$.

Choosing from the set $\mathrm{M}$ some elements, one can obtain a new set $\mathrm{S}$ that is a part of the set $\mathrm{M}$ then $\mathrm{S}$ is called a subset of $\mathrm{M}$. We also say that $\mathrm{S}$ is contained in $\mathrm{M}$ or that $\mathrm{M}$ contains $\mathrm{S}$.

If all sets are considered at a certain time and are subsets of a fixed universal set $\mathrm{U}$, then we can define a universal complement, or simply a complement of the set A, denoted by As, as the set of elements that belong to U, but do not belong to A, that is,

* Corresponding author: 1940@gmail.com 


$$
A^{\mathrm{c}}=\{\mathrm{x}: x \in U, x \notin A\}
$$

\section{Methods}

Sets with intersection operations, unions and complements that satisfy abstract laws [1], form an algebraic system, called the algebra of sets. This algebra is isomorphic to Boolean algebra and therefore often uses the ideas and terminology of Boolean algebra, but it should be noted that this terminology is not completely standardized, which sometimes leads to different names for the same concepts. Let us consider some concepts in more detail.

Let there be $n$ variables, each of which defines a certain set. The expression for the algebra of sets E (or a formula) is an expression composed of these variables, connected by means of operations of union, intersection and complement, for example

$$
\begin{aligned}
& \mathrm{E}_{1}=A \cap\left(B^{C} \cap C\right)^{C} \cup\left(A \cap B^{C} \cap C^{C}\right)^{C}, \\
& E_{2}=A \cap\left(B^{C} \cap C\right) \cup\left(A \cap B^{C} \cap C^{C}\right), \\
& E_{3}=\left(A \cap B^{C} \cap C\right) \cup\left(A \cap B^{C} \cap C^{C}\right), \\
& E_{4}=\left(A^{C} \cup B^{C}\right) \cap\left(A^{C} \cup B^{C} \cup C\right) \cap\left(B^{C} \cup C\right), \\
& E_{5}=\left(A^{C} \cup B \cup C\right) \cap\left(A \cup B^{C} \cup C\right) \cap\left(A^{C} \cup B^{C} \cup C\right)
\end{aligned}
$$

are expressions from three variables $\mathrm{A}, \mathrm{B}$ and $\mathrm{C}$.

Consider the following example. Let there be a list of employees of the enterprise who have access to the first object of a certain building (let's denote the list of their names as the set A). Let there also be a list of all those who have access to the second object (set B) and all those who have access to the third (set C). If now you need information about those who have access to the first and second objects simultaneously, then it will be necessary to select those who are simultaneously included in the first and second lists. For this, we need to find a new set that is the intersection of the original sets $\mathrm{A}$ and $\mathrm{B}$, i.e. find the set $\mathrm{A} \cap \mathrm{B}$. But this set does not contain information about whether these employees have access to the third object. Clearly, for this it is required to find another set that is the intersection of all three sets, i.e. the set $\mathrm{A} \cap \mathrm{B} \cap \mathrm{C}$. Suppose now that we need to make a list that contains the names of employees who have access to the first and second objects, but do not have a third entry. In this case it is necessary to find the set $\mathrm{A} \cap \mathrm{B} \cap \mathrm{C}^{\mathbf{c}}$. Considering such cases leads to the concept of fundamental products of the sets.

Suppose that there are $n$ distinct sets $A_{1}, A_{2}, A_{3}, \ldots, A_{n}$. The fundamental product of sets is a set of the form

$$
\mathrm{A}_{1}^{*} \cap \mathrm{A}_{2}^{*} \cap \mathrm{A}_{3}^{*} \cap \ldots \cap \mathrm{A}_{n}{ }^{*}
$$

where $\mathrm{A}_{i}^{*}$ is either $\mathrm{A}_{\mathrm{i}}$, or $\mathrm{A}_{i}^{c}$. We also note that

(1) There are exactly $2^{\text {n }}$ such fundamental products.

(2) Any two such fundamental products do not intersect.

(3) The universal set is the union of all such fundamental products

A variable is called a literal or a complement to a variable, for example $\mathrm{A}, \mathrm{A}^{\mathrm{C}}, \mathrm{B}^{\mathrm{C}}$, etc. A product is a literal or an intersection of two or more literals, such that no pair of them contains the same variable. For example, $\mathrm{B}^{\mathrm{C}} \cap \mathrm{C}, \mathrm{A} \cap \mathrm{B}^{\mathrm{C}} \cap \mathrm{C}^{\mathrm{C}}, \mathrm{A}, \mathrm{C}^{\mathrm{C}}$ - are products, and the expressions $\mathrm{A} \cap \mathrm{B}^{\mathrm{C}} \cap \mathrm{A}^{\mathrm{C}}$ and $\mathrm{A} \cap \mathrm{B}^{\mathrm{C}} \cap \mathrm{B}^{\mathrm{C}}$ - are not. We note that any intersection of literals is always reduced to either $\varnothing$ (empty set) or to the product. So, for example $\mathrm{A} \cap$ $\mathrm{B}^{\mathrm{C}} \cap \mathrm{A}^{\mathrm{C}}=\varnothing$, because $\mathrm{A} \cap \mathrm{A}^{\mathrm{C}}=\varnothing$ (by the law of the complement), and the intersection $\mathrm{A}$ $\cap \mathrm{B}^{\mathrm{C}} \cap \mathrm{B}^{\mathrm{C}}=\mathrm{A} \cap \mathrm{B}^{\mathrm{C}}$, because $\mathrm{B}^{\mathrm{C}} \cap \mathrm{B}^{\mathrm{C}}=\mathrm{B}^{\mathrm{C}}$ (by the law of the idempotency).

If for $\mathrm{n}$ variables the product consists of $\mathrm{n}$ literals, then it is called a fundamental product (some authors call any product a fundamental product). 
An expression that is the union of different products, if there is not a single work in it that is included in another work, is called the sum of products, or the normal form of the union of intersections, or a polynomial in normal form. From the previous example, $E_{1}$ is simply an expression, $E_{2}$ and $E_{3}$ are expressions in the normal form of the union of intersections.

If the expression consists of a union of fundamental products, then such an expression is called the complete normal form of the union of intersections, or a polynomial in the canonical form. The polynomial $\mathrm{E}_{3}$, in addition to having a normal form of intersection, is also a polynomial having a complete normal form of union of intersections.

Similarly, if for $\mathrm{n}$ variables the union consists of $\mathrm{n}$ literals, then it is called a fundamental union, and if you replace the union operations with the intersection operations, and the intersection operations in the join operation, you can get the normal intersection form and the complete normal intersection form. The expression $\mathrm{E}_{4}$ has the normal form of intersection of unions, and $\mathrm{E}_{5}$ is the complete normal form of intersection of unions [2].

Any expression can be converted to an equivalent expression that has a normal form. One of the differences of the normal form is that in this expression the complement operation is applied only to variables. To get rid of the complements applied to the expressions, we must apply the De Morgan's laws.

\section{Results}

Algorithm 1 for converting the expression to the normal form of combining intersections.

Let there be an initial expression for the algebra of sets E.

Step 1. Using De Morgan's laws and involutions, we give each parenthesis to which the addition operation is applied, to the form in which the addition operation applies only to variables.

Step 2. Using the distributive law of a union with respect to the intersection, we break up the brackets containing the unions of literals with respect to the intersection operations.

Step 3. Using the associative laws, complements and idempotency, we transform every intersection of literals either in $\varnothing$ or in a product.

Step 4. Using the laws of absorption and identity, we simplify the expression E and if it consists of a union of intersections, then the normal form is obtained, if not, then go to Step 2.

The laws of absorption for the algebra of sets have the form

$\mathrm{A} \cap(\mathrm{A} \cup \mathrm{B})=\mathrm{A}$

$\mathrm{A} \cup(\mathrm{A} \cap \mathrm{B})=\mathrm{A}$

Example 1.

We apply this algorithm to transform to the normal form of the following expression $\mathrm{E}=\left(\left(\mathrm{A} \cap \mathrm{B}^{\mathrm{C}}\right) \cup\left(\mathrm{B} \cap \mathrm{C}^{\mathrm{C}}\right)^{\mathrm{C}}\right) \cap\left(\left((\mathrm{B} \cap \mathrm{C}) \cup\left(\mathrm{A}^{\mathrm{C}} \cap \mathrm{C}\right)\right)^{\mathrm{C}} \cup(\mathrm{A} \cap \mathrm{B})\right)$.

Step 1. Using De Morgan's laws and involutions, we obtain $\mathrm{E}=\left(\left(\mathrm{A} \cap \mathrm{B}^{\mathrm{C}}\right) \cup \mathrm{B}^{\mathrm{C}} \cup \mathrm{C}\right) \cap\left(\left(\mathrm{B}^{\mathrm{C}} \cup \mathrm{C}^{\mathrm{C}}\right) \cap\left(\mathrm{A} \cup \mathrm{C}^{\mathrm{C}}\right) \cup(\mathrm{A} \cap \mathrm{B})\right)$.

Step 2. Using the law of distributive, we expand the brackets in the right side of expression

$$
\mathrm{E}=\left(\left(\mathrm{A} \cap \mathrm{B}^{\mathrm{C}}\right) \cup \mathrm{B}^{\mathrm{C}} \cup \mathrm{C}\right) \cap\left(( \mathrm { A } \cap \mathrm { B } ^ { \mathrm { C } } ) \cup ( \mathrm { B } ^ { \mathrm { C } } \cap \mathrm { C } ^ { \mathrm { C } } ) \cup ( \mathrm { A } \cap \mathrm { C } ^ { \mathrm { C } } ) \cup \left(\mathrm{C}^{\mathrm{C}}\right.\right.
$$
$\left.\left.\cap \mathrm{C}^{\mathrm{C}}\right) \cup(\mathrm{A} \cap \mathrm{B})\right)$.

Step 3. Let's transform the intersection of literals into a product

$\mathrm{E}=\left(\left(\mathrm{A} \cap \mathrm{B}^{\mathrm{C}}\right) \cup \mathrm{B}^{\mathrm{C}} \cup \mathrm{C}\right) \cap\left(\left(\mathrm{A} \cap \mathrm{B}^{\mathrm{C}}\right) \cup\left(\mathrm{B}^{\mathrm{C}} \cap \mathrm{C}^{\mathrm{C}}\right) \cup\left(\mathrm{A} \cap \mathrm{C}^{\mathrm{C}}\right) \cup \mathrm{C}^{\mathrm{C}} \cup\right.$ $(\mathrm{A} \cap \mathrm{B}))$.

Step 4. Since the $B^{C}$ is included in the $A \cap B^{C}$, then the $A \cap B^{C}$ is absorbed, the $C^{C}$ is also included in the $\mathrm{B}^{\mathrm{C}} \cap \mathrm{C}^{\mathrm{C}}$ and $\mathrm{A} \cap \mathrm{C}^{\mathrm{C}}$, so both these intersections are absorbed and the expression $\mathrm{E}$ takes the following form 
$\mathrm{E}=\left(\mathrm{B}^{\mathrm{C}} \cup \mathrm{C}\right) \cap\left(\left(\mathrm{A} \cap \mathrm{B}^{\mathrm{C}}\right) \cup \mathrm{C}^{\mathrm{C}} \cup(\mathrm{A} \cap \mathrm{B})\right)$.

Here again, we need to discard the brackets, so go to Step 2.

Step 2. Open the brackets and get

$$
\mathrm{E}=\left(\mathrm{A} \cap \mathrm{B}^{\mathrm{C}} \cap \mathrm{B}^{\mathrm{C}}\right) \cup\left(\mathrm{B}^{\mathrm{C}} \cap \mathrm{C}^{\mathrm{C}}\right) \cup\left(\mathrm{A} \cap \mathrm{B} \cap \mathrm{B}^{\mathrm{C}}\right) \cup\left(\mathrm{A} \cap \mathrm{B}^{\mathrm{C}} \cap \mathrm{C}\right)
$$
$\cup\left(\mathrm{C} \cap \mathrm{C}^{\mathrm{C}}\right) \cup(\mathrm{A} \cap \mathrm{B} \cap \mathrm{C})$.

Step 3. Let's transform the intersection of literals into a product

$\mathrm{E}=\left(\mathrm{A} \cap \mathrm{B}^{\mathrm{C}}\right) \cup\left(\mathrm{B}^{\mathrm{C}} \cap \mathrm{C}^{\mathrm{C}}\right) \cup \varnothing \cup\left(\mathrm{A} \cap \mathrm{B}^{\mathrm{C}} \cap \mathrm{C}\right) \cup \varnothing \cup(\mathrm{A} \cap \mathrm{B} \cap \mathrm{C})$.

Step 4. The intersection $A \cap B^{C}$ is included in $A \cap B^{C} \cap C$, so the latter is absorbed and the normal form for $\mathrm{E}$ has the form

$\mathrm{E}=\left(\mathrm{A} \cap \mathrm{B}^{\mathrm{C}}\right) \cup\left(\mathrm{B}^{\mathrm{C}} \cap \mathrm{C}^{\mathrm{C}}\right) \cup(\mathrm{A} \cap \mathrm{B} \cap \mathrm{C})$.

Let us consider the complete normal forms.

It should be noted that, by analogy with Boolean algebra, complete normal forms are sometimes called perfect normal forms. Consider the expression $\mathrm{E}=\mathrm{E}\left(\mathrm{x}_{1}, \mathrm{x}_{2}, \ldots, \mathrm{x}_{\mathrm{n}}\right)$, consisting of a union of products, i.e. represented in normal form. If every product consists of exactly $\mathrm{n}$ literals, then such an expression is called the complete normal form of the union of intersections.

Statement. Any expression of the algebra of sets can be transformed to an equivalent expression in its complete normal form, and such a representation is unique [3].

Proceeding from what was said above, one can see that any expression of the algebra of sets is transformed to an equivalent expression in normal form. Next, consider an algorithm that allows you to transform this expression into an equivalent expression in its full normal form. The idea of this algorithm is that if a product $\mathrm{P}$ in the expression $\mathrm{E}$ does not contain the $\mathrm{i}$-th variable, then it can be carried into $\mathrm{E}$, forming the product $\mathrm{P} \cap\left(\mathrm{x}_{\mathrm{i}} \cup \mathrm{x}\right.$ i) for $\mathrm{i} \leq \mathrm{n}$.

Algorithm 2 for converting the expression to the full normal form of combining intersections.

Step 1. Let there be an expression $\mathrm{E}=\mathrm{E}\left(\mathrm{x}_{1}, \mathrm{x}_{2}, \ldots \mathrm{x}_{\mathrm{n}}\right)$ represented in normal form. We find the product $\mathrm{P}$ in the expression $\mathrm{E}$, which does not contain the $\mathrm{i}$-th variable and form the product $\mathrm{P} \cap\left(\mathrm{x}_{\mathrm{i}} \mathrm{x}_{i}^{c}\right)$. This does not violate the equivalence of the expression, since $\left(\mathrm{x}_{\mathrm{i}} \cup \mathrm{x}_{i}^{c}\right)=\mathrm{U}$, and $\mathrm{P} \cap \mathrm{U}=\mathrm{P}$. Remove duplicate products (this is possible since $\mathrm{P} \cup$ $\mathrm{P}=\mathrm{P})$.

Step 2. Repeat Step 1 until each product in E becomes a fundamental product, i.e. each product will not include all $\mathrm{n}$ variables.

Example 2.

We apply this algorithm for the expression $\mathrm{E}$ in the normal form obtained in Example 1 to convert it to the full normal form.

$$
\mathrm{E}=\left(\mathrm{A} \cap \mathrm{B}^{\mathrm{C}}\right) \cup\left(\mathrm{B}^{\mathrm{C}} \cap \mathrm{C}^{\mathrm{C}}\right) \cup(\mathrm{A} \cap \mathrm{B} \cap \mathrm{C}) .
$$

Step 1. Find the product $A \cap \mathrm{B}^{\mathrm{C}}$, which does not contain the variable $\mathrm{C}$ and form the product $\left(\mathrm{A} \cap \mathrm{B}^{\mathrm{C}}\right) \cap\left(\mathrm{C} \cup \mathrm{C}^{\mathrm{C}}\right)$, we get

$$
\begin{aligned}
\mathrm{E} & =\left(\mathrm{A} \cap \mathrm{B}^{\mathrm{C}}\right) \cap\left(\mathrm{C} \cup \mathrm{C}^{\mathrm{C}}\right) \cup\left(\mathrm{B}^{\mathrm{C}} \cap \mathrm{C}^{\mathrm{C}}\right) \cup(\mathrm{A} \cap \mathrm{B} \cap \mathrm{C})= \\
& =\left(\mathrm{A} \cap \mathrm{B}^{\mathrm{C}} \cap \mathrm{C}\right) \cup\left(\mathrm{A} \cap \mathrm{B}^{\mathrm{C}} \cap \mathrm{C}^{\mathrm{C}}\right) \cup\left(\mathrm{B}^{\mathrm{C}} \cap \mathrm{C}^{\mathrm{C}}\right) \cup(\mathrm{A} \cap \mathrm{B} \cap \mathrm{C}) .
\end{aligned}
$$

Step 2. Since in $E$ there is a product $B^{C} \cap C^{C}$ that does not contain the variable $A$, then we go back to Step 1 and form the product $\left(\mathrm{B}^{\mathrm{C}} \cap \mathrm{C}^{\mathrm{C}}\right) \cap\left(\mathrm{A} \cup \mathrm{A}^{\mathrm{C}}\right)$, C).

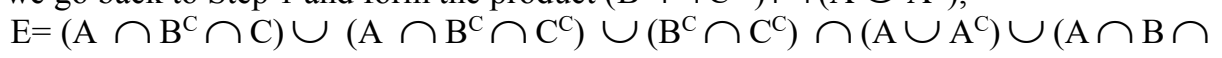

After the parentheses are opened in E, two identical fundamental products are formed $\mathrm{A} \cap \mathrm{B}^{\mathrm{C}} \cap \mathrm{C}^{\mathrm{C}}$. One of them must be removed. Now $\mathrm{E}$ is represented in the full normal form:

$$
\mathrm{E}=\left(\mathrm{A} \cap \mathrm{B}^{\mathrm{C}} \cap \mathrm{C}\right) \cup\left(\mathrm{A} \cap \mathrm{B}^{\mathrm{C}} \cap \mathrm{C}^{\mathrm{C}}\right) \cup\left(\mathrm{A}^{\mathrm{C}} \cap \mathrm{B}^{\mathrm{C}} \cap \mathrm{C}^{\mathrm{C}}\right) \cup(\mathrm{A} \cap \mathrm{B} \cap \mathrm{C}) .
$$


Thus, if there is an expression represented in normal form, then this algorithm allows algebraic transformations to bring it to the full normal form. However, this method is not the only one. For the same purpose, we can also use the Venn diagrams.

Let's consider an example. Let there be a partition of the set $U$ shown in Fig 1. We select the set given by the formula (the normal form of the union of intersections) $A \cup\left(B^{C}\right.$ $\cap \mathrm{C})$. It defines the union of two sets: $\mathrm{A}=[4]$ and a set representing the intersection of the sets $\mathrm{B}^{\mathrm{C}}$ and $\mathrm{C}$, i.e. of the set $\mathrm{B}^{\mathrm{C}} \cap \mathrm{C}=\{1,5\}$. Therefore, the set $\mathrm{A} \cup\left(\mathrm{B}^{\mathrm{C}} \cap \mathrm{C}\right)=\{1,4,5$, $6,7\}$. This set is shaded in Fig. 1 It can be seen from the diagram that the set $A \cup\left(B^{C} \cap C\right)$ is given by the union of five fundamental products: to the set $\{4\}$ there corresponds the fundamental product $\mathrm{A} \cap \mathrm{B}^{\mathrm{C}} \cap \mathrm{C}^{\mathrm{C}}$, the set $\{6\}-\mathrm{A} \cap \mathrm{B} \cap \mathrm{C}^{\mathrm{C}}$, the set $\{7\}-\mathrm{A} \cap \mathrm{B}$ $\cap \mathrm{C}$, the set $\{5\}-\mathrm{A} \cap \mathrm{B}^{\mathrm{C}} \cap \mathrm{C}$ and the set $\{1\}-\mathrm{A}^{\mathrm{C}} \cap \mathrm{B}^{\mathrm{C}} \cap \mathrm{C}$. The union of these fundamental products and gives a complete normal form
$\left(\mathrm{A} \cap \mathrm{B}^{\mathrm{C}}\right.$ $\left.\cap \mathrm{B}^{\mathrm{C}} \cap \mathrm{C}\right)$.

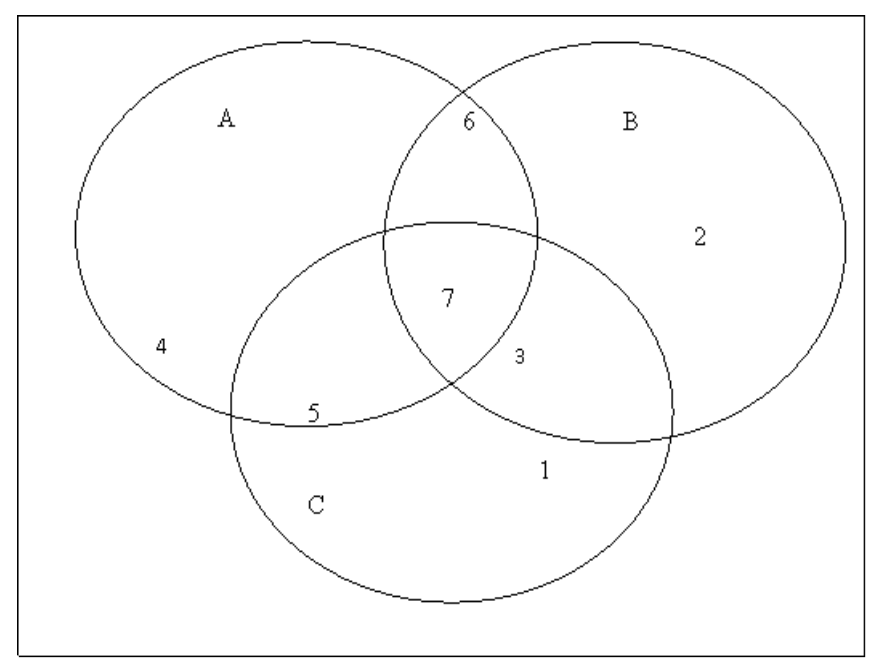

Fig. 1. Partition of the set.

We note that for any set there exists not only a single complete normal form of the union of intersections, but the only complete normal form of intersection of unions of sets. Each of these forms can be found in two ways. So for the set from the previous example A $\cup\left(\mathrm{B}^{\mathrm{C}} \cap \mathrm{C}\right)$ we open the brackets and get an expression in the normal form of intersection of unions $\left(\mathrm{A} \cup \mathrm{B}^{\mathrm{C}}\right) \cap(\mathrm{A} \cup \mathrm{C})$. In the first bracket there is no variable $\mathrm{C}$, and in the second variable B. Since the expression $\left(C \cap C^{C}\right)=\varnothing$, the following expression is equivalent to the original

$$
\begin{aligned}
& \left(\left(\mathrm{A} \cup{ }_{\mathrm{B}}^{\mathrm{C}}\right) \cup\left(\mathrm{C} \cap \mathrm{C}^{\mathrm{C}}\right)\right) \cap\left(\left(\mathrm{A} \cup_{\mathrm{C}}\right) \cup\left(\mathrm{B} \cap \mathrm{B}^{\mathrm{C}}\right)\right)= \\
& =\left(A \cup{ }_{B} \cup_{C}\right) \cap\left(A \cup{ }_{B} \cup_{C^{C}}\right) \cap\left(A \cup \cup_{B} \cup_{C}\right) \cap\left(A \cup{ }_{B} \cup_{C} \cup_{C}\right) \\
& =\left(A \cup_{B^{C}} \cup_{C}\right) \cap\left(A \cup_{B^{C}} \cup_{C^{C}}\right) \cap\left(A \cup_{B} \cup_{C}\right) \text {. }
\end{aligned}
$$

The last expression is the complete normal form of intersection of unions for the original formula.

You can also find this expression using the Venn diagram. Since the elements $\{0,2$, $3\}$ do not enter the initial set $\{1,4,5,6,7\}$, it is necessary to form the intersection of such unions that do not contain these three sets. The union $A \cup_{B} \cup_{C}$ does not contain the element $\{0\}$, the union $\mathrm{A} \cup_{\mathrm{B}^{\mathrm{C}}} \cup_{\mathrm{C}}$ does not contain the element $\{2\}$ and the union $\mathrm{A} \cup$ 
$\mathrm{B}^{\mathrm{C}} \cup \mathrm{C}^{\mathrm{C}}$ does not contain the element $\{3\}$. Hence, forming an intersection of them, one can obtain the complete normal form of intersection of unions of sets.

$\left(\mathrm{A} \cup_{\mathrm{B}} \cup_{\mathrm{C}}\right) \cap\left(\mathrm{A} \cup_{\mathrm{B}^{\mathrm{C}}} \cup_{\mathrm{C}}\right) \cap\left(\mathrm{A} \cup_{\mathrm{B}^{\mathrm{C}}} \cup_{\mathrm{C}^{\mathrm{C}}}\right)$.

\section{Discussion}

Abstract algebra deals with the study of operations performed on certain elements. By now, the ideas of abstract algebra are used not only for mathematical methods, but also allow us to obtain practical results. The union, intersection, and complement operations performed on sets satisfy certain laws (or identities) and form an algebra of sets. Since the numerical algebra appeared earlier, the question arises which of the operations (intersection or union) is "similar" to the operation of adding numbers and which is to the operation of multiplication [5]. It is hardly possible to answer this question. For numbers, for example, only the distributivity of multiplication with addition is satisfied, and in the algebra of sets, two distributivity laws are considered: intersections with respect to union and union with respect to intersection.

Important in the execution of operations is their priority. First, the addition operation is performed, then the intersection and then the join.

The set can be given by different formulas. Although these formulas look different, but they all are equivalent in the sense that they define the same elements of a given set. For example, suppose there are two expressions in normal form

$$
\begin{aligned}
& \mathrm{E}_{1}=(\mathrm{B} \cap \mathrm{C}) \cup\left(\mathrm{A}^{\mathrm{C}} \cap \mathrm{C}^{\mathrm{C}}\right), \\
& \mathrm{E}_{2}=(\mathrm{B} \cap \mathrm{C}) \cup\left(\mathrm{A}^{\mathrm{C}} \cap \mathrm{B}\right) \cup\left(\mathrm{A}^{\mathrm{C}} \cap \mathrm{B}^{\mathrm{C}} \cap \mathrm{C}^{\mathrm{C}}\right) .
\end{aligned}
$$

These formulas are equivalent, which is easy to verify if one transforms each of them to a complete normal form, which is the same for both $E_{1}$ and $E_{2}$

\section{$(\mathrm{A} \cap \mathrm{B} \cap \mathrm{C}) \cup\left(\mathrm{A}^{\mathrm{C}} \cap \mathrm{B} \cap \mathrm{C}\right) \cup\left(\mathrm{A}^{\mathrm{C}} \cap \mathrm{B} \cap \mathrm{C}^{\mathrm{C}}\right) \cup\left(\mathrm{A}^{\mathrm{C}} \cap \mathrm{B}^{\mathrm{C}} \cap \mathrm{C}^{\mathrm{C}}\right)$.}

In order to determine which of the equivalent formulas is "simpler" we introduce the following notation. Let $\mathrm{E}$ be an expression in normal form and let $\mathrm{L}$ (E) be the number of literals in this expression (all occurrences are assumed) and $\mathrm{F}(\mathrm{E})$ is the number of products from which is formed $\mathrm{E}$. For $\mathrm{E}_{1}$, the value $\mathrm{L}\left(\mathrm{E}_{1}\right)=2+2=4$ and $\mathrm{F}\left(\mathrm{E}_{1}\right)=2$, and $\mathrm{L}\left(\mathrm{E}_{2}\right)=2$ $+2+3=7$ and $\mathrm{F}\left(\mathrm{E}_{2}\right)=3$.

Let $E_{1}$ and $E_{2}$ be equivalent expressions in normal form. Then $E_{1}$ is simpler than $E_{2}$ if

$\mathrm{L}\left(\mathrm{E}_{1}\right)<\mathrm{L}\left(\mathrm{E}_{2}\right)$ and $\mathrm{F}\left(\mathrm{E}_{1}\right) \leq \mathrm{L}\left(\mathrm{E}_{2}\right)$ or

$\mathrm{L}\left(\mathrm{E}_{1}\right) \leq \mathrm{L}\left(\mathrm{E}_{2}\right)$ and $\mathrm{F}\left(\mathrm{E}_{1}\right)<\mathrm{L}\left(\mathrm{E}_{2}\right)$.

The expression E, represented in normal form, is called minimal if there is no other equivalent expression that is simpler than E. It should be noted that there may be more than one equivalent minimal expression.

As shown in [6], for each formula there exists its minimal representation, which is very important when using similar discrete models for real applied problems. In the above article, we showed in detail how the minimization of formulas for the algebra of sets is performed using the methods of graph theory.

\section{Conclusions}

Proceeding from the above, one can see that the technology of using the algebra of sets formulas opens a very promising way of constructing discrete models in various directions of development in construction and economy 


\section{References}

1. Buiding Codes and Regulations SNiP 23.05.95* (2005)

2. A.A. Kazansky, L.V. Larina, Informatics, 15(304) (2001)

3. A.A. Kazansky, L.V. Larina, Informatics, 14 (255), (2000)

4. A. Zaychenko, S. Gutman, O. Kalinina, Advances in Intelligent Systems and Computing, 692, 453-462 (2018) DOi - 10.1007/978-3-319-70987-1_48

5. A.A. Kazansky, Modern science success, 1, 6 (2017)

6. O.V. Kalinina, M.V. Lopatin, Actual Problems of Economics, 182, 392-405 (2016) 